\title{
Conformational change of Dishevelled plays a key regulatory role in the Wnt signaling pathways
}

\author{
Ho-Jin Lee ${ }^{1}$, De-Li Shi ${ }^{2,3 *}$, Jie J Zheng ${ }^{1,4 *}$ \\ ${ }^{1}$ Department of Structural Biology, St. Jude Children's Research Hospital, Memphis, \\ United States; ${ }^{2}$ Laboratoire de biologie du développement, Institut de Biologie \\ Paris-Seine, Sorbonne Universités, Paris, France; ${ }^{3}$ School of Life Sciences, Shandong \\ University, Jinan, China; ${ }^{4}$ Departments of Ophthalmology, David Geffen School of \\ Medicine at University of California, Los Angeles, Los Angeles, United States
}

Abstract The intracellular signaling molecule Dishevelled (Dvl) mediates canonical and noncanonical Wnt signaling via its PDZ domain. Different pathways diverge at this point by a mechanism that remains unclear. Here we show that the peptide-binding pocket of the Dvl PDZ domain can be occupied by Dvl's own highly conserved C-terminus, inducing a closed conformation. In Xenopus, Wnt-regulated convergent extension (CE) is readily affected by Dvl mutants unable to form the closed conformation than by wild-type Dvl. We also demonstrate that while Dvl cooperates with other Wnt pathway elements to activate canonical Wnt signaling, the open conformation of Dvl more effectively activates Jun N-terminal kinase (JNK). These results suggest that together with other players in the Wnt signaling pathway, the conformational change of Dvl regulates Wnt stimulated JNK activity in the non-canonical Wnt signaling.

DOI: 10.7554/eLife.08142.001

*For correspondence: de-li.shi@ upmc.fr (D-LS); jzheng@jsei.ucla. edu (JJZ)

Competing interests: The authors declare that no competing interests exist.

Funding: See page 13

Received: 15 April 2015

Accepted: 21 August 2015

Published: 22 August 2015

Reviewing editor: Jeremy Nathans, Howard Hughes Medical Institute, Johns Hopkins University School of Medicine, United States

(c) Copyright Lee et al. This article is distributed under the terms of the Creative Commons Attribution License, which permits unrestricted use and redistribution provided that the original author and source are credited.

\section{Introduction}

The multiple Wnt signaling-related pathways are crucial to various developmental processes (Logan and Nusse, 2004; Angers and Moon, 2009). By regulating the cellular $\beta$-catenin level, canonical Wnt signaling controls cell fate, while non-canonical Wnt signaling plays a key role in controlling convergent extension (CE) and polarized cellular orientation. Dishevelled (Dvl, or Dsh in Drosophila), a key component of both Wnt signaling pathways, relays Wnt signals downstream from the membrane-bound Wnt receptor Frizzled (Fz) (Noordermeer et al., 1994; Theisen et al., 1994; Axelrod et al., 1998; Wong et al., 2003; Park et al., 2005; Wang et al., 2006; Schwarz-Romond et al., 2007; Simons et al., 2009). While Dvl mediates both canonical and non-canonical Wnt signals, different pathways diverge at this point. Therefore, Dvl has been described as the 'policeman' at the intersection who directs different Wnt signals in different directions (Boutros and Mlodzik, 1999). However, the mechanism by which Dvl relays Wnt signals from Fz to different downstream components is not well understood.

Dvl contains highly conserved DIX, PDZ, and DEP domains and a highly conserved extreme C-terminus (Figure 1) (Wharton, 2003; Wallingford and Habas, 2005). The PDZ and DIX domains are reported to be involved in canonical Wnt signaling, while the PDZ and DEP domains play a crucial role in non-canonical Wnt signaling (Sokol et al., 1995; Axelrod et al., 1998; Boutros et al., 1998; Li et al., 1999; Moriguchi et alı, 1999; Yamanaka et alı, 2002; Gao et alı, 2010). The central PDZ domain not only participates in both pathways but also binds directly to the membrane-bound Wnt receptor Fz (Wong et al., 2003). Many Wnt signaling regulators have been reported to mediate the different Wnt signaling pathways by interacting directly with the PDZ domain of Dvl 
eLife digest The development of an animal embryo depends on a number of signaling pathways that pass information from the outside of the cell to the inside. These pathways include Wnt signaling, which also regulates cell growth. The pathways must be precisely controlled; abnormal Wnt activity has been implicated in several human diseases, ranging from heart disease to cancer.

Wnt signaling is complex, and actually comprises two major pathways: the canonical pathway (which depends on a protein called $\beta$-catenin) and the PCP pathway (which doesn't depend on $\beta$-catenin). Both pathways are triggered when Wnt molecules bind to receptors on the outside of the cell. These receptors pass the signal into the cell and to a protein called 'Dishevelled' (or 'Dvl' for short). This protein then passes the signal on through either the canonical or PCP pathway.

Nevertheless it is not clear how the Dishevelled protein can direct the signal specifically down either one of these pathways.

Lee et al. now show that the Dishevelled protein can take on at least two different shapes. When it is 'closed', one end of the protein is tucked inside a pocket elsewhere on the protein's surface. But when Dishevelled is 'open', this end of the protein moves out of this pocket. Further experiments using frogs (called Xenopus, which are commonly used in research) reveal that mutant versions of Dishevelled that were unable to take on the closed form strongly affected an aspect of the frog's development that involves the PCP pathway.

Lee et al. then demonstrate that while Dishevelled cooperates with several other Wnt pathway components to activate the canonical pathway, the open form of Dishevelled activates the PCP pathway. The next challenge following on from this work is to find out how Wnt molecules binding to the receptor trigger the shape change in Dishevelled.

DOI: 10.7554/eLife.08142.002

(Wharton, 2003; Wallingford and Habas, 2005; Gao and Chen, 2009). Notably, in most species the extreme C-terminus of Dvl resembles a class III PDZ-binding motif (E/D-X- $\Phi$, where $\Phi$ represents hydrophobic residues such as $F, I, L, M$, or V), while that of Dsh resembles a class II PDZ-binding motif (Ф-X-Ф) (Figure 1) (Tonikian et al., 2008; Lee and Zheng, 2010). Because these two motifs suggest the possibility of intramolecular binding, we hypothesized that the C-terminus of Dvl/Dsh binds intrinsically to the Dvl PDZ domain.

Here we use biophysical methods to investigate the interaction of the Dvl extreme C-terminus with the Dvl PDZ domain and demonstrate that Dvl adopts a closed conformation. We also show, in a Xenopus model, that disruption of this intramolecular interaction activates Jun $\mathrm{N}$-terminal kinase (JNK) and enhances the CE phenotype associated with activation of non-canonical Wnt signaling. Further, we demonstrate that a Dvl PDZ-binding peptide or small molecule that inhibits canonical $\beta$-catenin signaling enhances JNK activity by releasing the Dvl C-terminus from its autoinhibitory closed conformation.

\section{Results}

\section{The Dvl C-terminus and PDZ domain directly interact}

After our initial pull-down test indicated that Dvl C-terminus might interact with the Dvl PDZ domain, we decided to use two different biophysical assays to determine the binding affinity of the DVl PDZ domain for the Dvl-C peptide and for a peptide derived from the C-terminus of Drosophila Dsh ('Dsh-C peptide'). We first used a competitive binding assay. Binding of the PDZ domain to a fluorescently-labeled peptide (Rox-DprC) derived from the C-terminus of Dapper (Dpr), a known binding partner of the Dvl PDZ domain (Cheyette et al., 2002), was monitored by fluorescence polarization. Both Dvl-C and Dsh-C peptides competitively inhibited the interaction of Rox-DprC with the Dvl-1 PDZ domain (Figure 2), indicating that the three peptides competed for the same binding site on the PDZ domain. The inhibition constants $\left(\mathrm{K}_{1}\right)$ calculated from two independent experiments $(12.3 \pm 7.8 \mu \mathrm{M}$ for the Dvl-C peptide and $26.8 \pm 8.4 \mu \mathrm{M}$ for the Dsh-C peptide) were similar to the binding affinity of Rox-DprC to the PDZ domain $\left(K_{D} \sim 7.9 \pm 0.9 \mu \mathrm{M}\right)$ (Lee et al., 2009a, 2009b). We then measured the binding between Dvl-C and the Dvl-1 PDZ domain by isothermal titration calorimetry (ITC) (Figure 3) and obtained a $K_{D}$ of $7.0 \pm 0.7 \mu \mathrm{M}$, which is consistent with the $K_{1}$ value observed in the fluorescence study. 


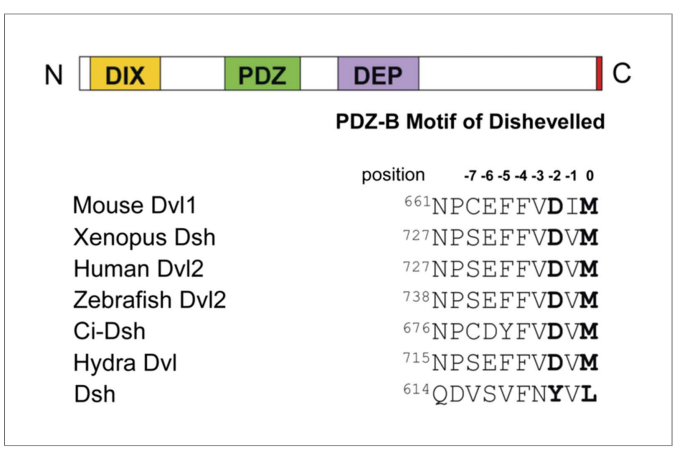

Figure 1. The C-terminal tail of Dishevelled (Dvl) is a PDZ domain binding motif. Sequence alignment of the C-terminus of Dvl/Dsh from selected species (Wallingford and Habas, 2005), showing residue numbers. DOI: 10.7554/eLife.08142.003

domain with higher binding affinity than the Dsh-C peptide does and that the complex is formed in the intermediate exchange range on the NMR time scale.

To structurally analyze the binding of the Dvl-1 PDZ domain and the Dvl-C peptide, we determined the solution structure of the complex that formed (Figure 5). The Dvl PDZ domain contains six $\beta$-strands $(\beta \mathrm{A} \sim \beta \mathrm{F})$ and two $\alpha$-helix $(\alpha \mathrm{A}$ and $\alpha \mathrm{B})$ structures (Wong et alı, 2003; Lee et al., 2009a, $2009 \mathrm{~b}$ ). As expected, we found that the Dvl-C peptide fits into the $\alpha B / \beta B$ peptide-binding groove of the Dvl PDZ domain and forms an additional $\beta$-strand with the $\alpha B$-structure of the Dvl PDZ domain (Figure 5A-C). Nuclear Overhauser effect (NOE) data indicated that six residues in the Dvl-C peptide participate in binding (Figure 5-source data 1, 2). The side chain of Met(0) in the Dvl-C peptide is located within a hydrophobic pocket formed by the side chains of residues Leu262, lle264, and

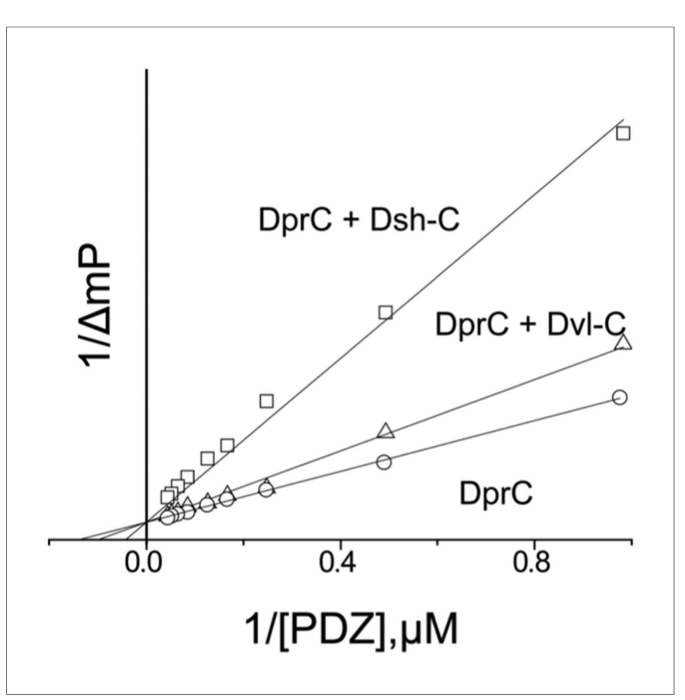

Figure 2. Competitive binding experiments. The $K_{D}$ value of the fluorescence-labeled Dapper (Dpr)-derived peptide Rox-DprC was obtained by plotting $1 / \Delta \mathrm{mP}$ vs $1 /[P D Z]$, where $\triangle m P$ is the fluorescence polarization change ( $\times 1000)$ of Rox-DprC and [PDZ] is the concentration of the PDZ domain of Dvl. The $K_{1}$ values of the Dvl-C and Dsh-C peptides were obtained by using the equation $K_{D}{ }^{\text {app }}=\left(K_{D} /\left(1+[l] / K_{l}\right)\right)$.

DOI: 10.7554/eLife.08142.004
Ile266 in the $\beta B$-structure and residues Val325, Leu321, and Val318 in the $\alpha B$-helix structure (Figure 5C,D). Notably, the side chain of residue Asp(-2) in the Dvl-C peptide forms a hydrogen bond with the side chain of residue Arg322 in the Dvl PDZ domain (Figure 5E). Consistent with this finding, the Arg322Ala substitution dramatically weakened the binding of Dvl PDZ to the Dvl-C peptide (Figure 5-figure supplement 1) (Lee et al., 2009a). The side chains of two hydrophobic Dvl-C residues, Val(-3) and Phe (-5), interact with the side chains of the Val318 and Ile266 residues in the DvI PDZ domain (Figure 5E).

\section{The binding pocket of DvI PDZ is occupied by its intrinsic C-terminus}

To verify that the binding pocket of the Dvl PDZ domain is occupied by the intrinsic C-terminus, we generated two constructs: $\mathrm{mC} 1$ (residues 251-695 of mouse Dvl-1), containing the PDZ and DEP domains (with an intact PDZ-binding motif) and $\mathrm{mC1}-\mathrm{C} \Delta 7$ (residues 251-688), lacking the PDZ-binding motif. We then examined the binding of Rox-DprC to the two constructs. Little polarization change was observed when $\mathrm{mC} 1$ proteins were added to Rox-DprC solution, whereas large polarization changes were induced 


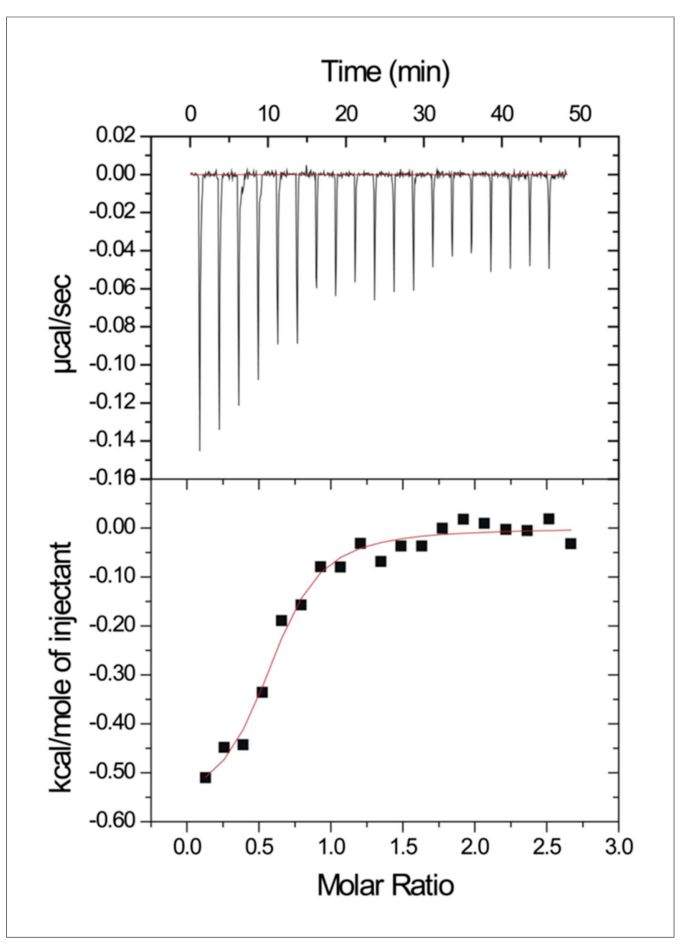

Figure 3. Isothermal titration calorimetry experiment. The MicroCal Auto-iTC-200 was used to obtain the binding affinity of Dvl-C peptide and DvI PDZ protein in $50 \mathrm{mM}$ phosphate buffer. The concentration of Dvl-C peptide in the syringe was $1.05 \mathrm{mM}$ and the concentration of Dvl PDZ domain in the cell was $0.114 \mathrm{mM}$. The $K_{D}$ value was averaged from two independent experiments at $25^{\circ} \mathrm{C}$.

DOI: 10.7554/eLife.08142.005 by adding $\mathrm{mC} 1-\mathrm{C} \Delta 7$ (Figure 6), indicating that the binding pocket of the Dvl PDZ domain was occupied by its intrinsic C-terminus in the $\mathrm{mC} 1$ construct. The binding affinity between Rox-DprC and $\mathrm{mC} 1-\mathrm{C} \Delta 7$ was $3.7 \pm 0.5 \mu \mathrm{M}$, closely approximating the affinity between Rox-DprC and the Dvl-1 PDZ domain. In contrast, the estimated binding affinity between Rox-DrpC and $\mathrm{mD} 1$ was greater than $70 \mu \mathrm{M}$, suggesting not only that the Dvl PDZ domain binds intrinsically to the Dvl C-terminus but also that this binding interferes with interactions between the Dvl PDZ domain and its other binding partners in the Wnt signaling pathways.

\section{Dvl conformational change significantly affects Wnt- regulated cell polarity}

After establishing that Dvl can adopt a 'closed' conformation in which its $\mathrm{C}$-terminus binds to its PDZ domain, we used a Xenopus model (Xenopus Dvl-2, XDsh) (Sokol et al., 1995; Sokol, 1996; Umbhauer et al., 2000) to investigate how this intrinsic interaction affects the role(s) of Dvl in the Wnt signaling pathways. We first generated two constructs, both myc-tagged at the $\mathrm{N}$-terminus: wild-type XDsh (residues 1-732) (Sokol, 1996) and mutant $X D$ sh-C $\Delta 8$ (residues 1-724, lacking the C-terminal PDZ-binding motif and therefore unable to form the intrinsic interaction between the its PDZ domain and the C-terminus). To avoid interfering the function of Dvl C-terminus, we placed the myc-tag at the $\mathrm{N}$-terminus. However, the tag may affect the $\mathrm{N}$-terminal DIX domain or potentially have some nonspecific effects. Therefore, in the Xenopus studies, we always paired the two constructs in the experiments to minimalize the potential of unexpected effects.

To examine canonical Wnt signaling, we used a luciferase assay with a siamois promoter reporter (Brannon et al., 1997). The Xenopus Wnt target gene construct with siamois promoter-driven luciferase reporter and equivalent quantities of XDsh-C $\Delta 8$ and wild-type XDsh mRNA, respectively, were coinjected into the animal pole region of 2-cell Xenopus embryos, and luciferase activity was then assayed in ectodermal explants dissected at the late blastula stage. Three different doses ( $80 \mathrm{pg}$, $200 \mathrm{pg}$, and $500 \mathrm{pg}$ ) of XDsh and XDsh-C $\Delta 8$ mRNAs were used. At low and intermediate doses, neither XDsh nor XDsh-C $\Delta 8$ substantially affected canonical Wnt signaling (not shown). At the high dose, both constructs enhanced canonical Wnt signaling, but wild-type XDsh was a stronger activator (Figure 7), consistent with a previous report showing involvement of the extreme C-terminal region of Dvl in activation of canonical Wnt signaling (Tauriello et al., 2012).

To examine how the conformational change of Dvl affects the Wnt-regulated CE phenotype (associated with the non-canonical Wnt signaling), we injected three different doses of wild-type XDsh and of XDsh-C $\Delta 8$ mRNA into the dorsal blastomeres of 4-cell Xenopus embryos. At all three doses $(80$ pg, 200 pg, and 500 pg), XDsh-C $\Delta 8$ mRNA caused greater body axis shortening and dorsal tail flexion than did wild-type $X D$ sh (Figure $8 A$ ), suggesting that $X D$ sh-C $\Delta 8$ is more active than wild-type XDsh in inducing the CE phenotype. We then compared Xdsh-C $\Delta 8$ with another Dvl mutant that lacks the PDZ domain, the well-established Xdd1 (Sokol, 1996). Like XDsh-C $\Delta 8$, Xdd1 is in 'open' conformation because it has no PDZ domain to interact with its $\mathrm{C}$-terminus. We injected equal quantities (500 pg) of N-terminal myc-tagged Xdd1, XDsh-CA8, and wild-type XDsh mRNA, respectively, into the dorsal blastomeres of 4-cell Xenopus embryos and found that the phenotypes 


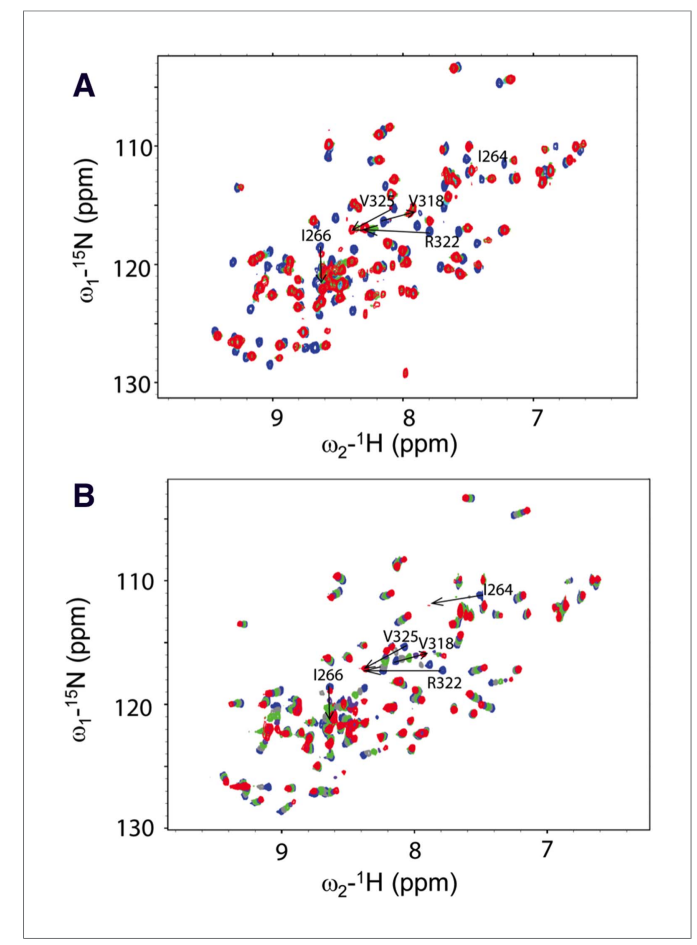

Figure 4. Direct interaction of the Dvl C-terminus and PDZ domain. (A) Overlap of ${ }^{1} \mathrm{H}-{ }^{15} \mathrm{~N} \mathrm{HSQC}$ spectra of ${ }^{15} \mathrm{~N}$-labeled PDZ domain without (blue) and with the unlabeled peptide (SEFFVDVM) derived from the extreme C-terminus of Dvl. Free: blue; final: red; ratio of peptide: protein $=20: 1$. (B) Overlap of ${ }^{1} \mathrm{H}_{-}{ }^{15} \mathrm{~N}$ HSQC spectra of ${ }^{15} \mathrm{~N}$-labeled PDZ domain without (blue) and with unlabeled peptide (QDVSVSNYVL) derived from the C-terminus of Drosophila Dsh (Dsh-C). Blue: free; red: final; ratio of peptide: protein $=20: 1$.

DOI: 10.7554/eLife.08142.006 were very similar after injection of $X D s h-C \Delta 8$ and after injection of $\mathrm{Xdd} 1$ (Figure $8 \mathrm{~B}$ ), suggesting that the 'open' Dvl is more active than the 'closed' wild-type Dvl in inducing the Xenopus CE phenotype.

\section{The open conformation of Dvl activates JNK more effectively}

In Xenopus embryos, JNK is known to regulate CE through non-canonical Wnt-PCP signaling (Sokol, 1996, 2000; Jones and Chen, 2007), and either hyperactivation or JNK depletion dysregulates CE (Yamanaka et al., 2002). We therefore investigated how the change of DVl conformation affects JNK activity. We overexpressed wild-type XDsh, Xdd1, and $\mathrm{XDsh}-\mathrm{C} \Delta 8$ in the ventral regions of 4 -cell Xenopus embryos and dissected the ventral regions at the early gastrula stage to examine JNK phosphorylation by western blot. Overexpression of wild-type XDsh induced slightly greater JNK phosphorylation than observed in uninjected control cells. However, both Xdd1 and XDsh-C $\Delta 8$ induced JNK phosphorylation more potently (Figure 9A), suggesting that deletion of the XDsh C-terminal region renders $X D$ sh more active in the noncanonical Wnt pathway. This finding is consistent with an early report of more effective JNK activation in COS-7 cells expressing mutant Dvl lacking the PDZ domain than in cells expressing wild-type Dvl (Sokol et al., 1995; Axelrod et al., 1998; Li et al., 1999; Moriguchi et al., 1999; Yamanaka et al., 2002; Gao et al., 2010).

To further demonstrate that the conforma-

tion of Dvl regulates its activation of JNK, we used the AP1-luciferase reporter (Rui et al., 2007) to monitor JNK activation in whole Xenopus embryos. When equal quantities (500 pg) of XDsh-C 48 or wild-type XDsh mRNA were injected into the dorsal region of 4-cell Xenopus embryos and luciferase activity was assayed at the late gastrula stage, XDsh-C $\Delta 8$ clearly activated AP1-luciferase activity more strongly (Figure 9B), indicating that DVl in the open conformation activates JNK more potently than Dvl in the closed conformation.

To clarify the role of the Dvl C-terminus in JNK activation, we analyzed activin-induced changes in the length and shape of Xenopus ectodermal explants; these changes represent the CE phenotype associated with non-canonical Wnt signaling (Figure $9 \mathrm{C}-\mathrm{H})$. In Xenopus, both activation and inhibition of non-canonical Wnt signaling result in planar cell polarity (PCP) defects and produce CE phenotype (Djiane et al., 2000). Ectodermal explants from control embryos and embryos injected with different mRNAs that encode Dvl and different mutants were dissected at the early blastula stage and treated with activin. The phenotypes were monitored at equivalent early neurula stages. As expected, XDsh$C \Delta 8$ and the dominant-negative mutant Xdd1 strongly inhibited the activin-induced elongation of ectodermal explants (CE outcomes) as compared to controls, while wild-type XDsh had little effect (Figure 9D-F). However, co-expression of a dominant-negative JNK mutant (dnJNK), which inhibits non-canonical Wnt signaling (Yamanaka et al., 2002; Carron et al., 2005), with XDsh-C 88 or Xdd1 efficiently rescued explant elongation (Figure 9G,H), indicating that the CE defects induced by $\mathrm{XDsh}-\mathrm{C} \Delta 8$ and $\mathrm{Xdd} 1$ are the result of JNK activation. In addition, we also confirmed that co-expression of dnJNK with XDsh could also rescue explant elongation (not shown). 


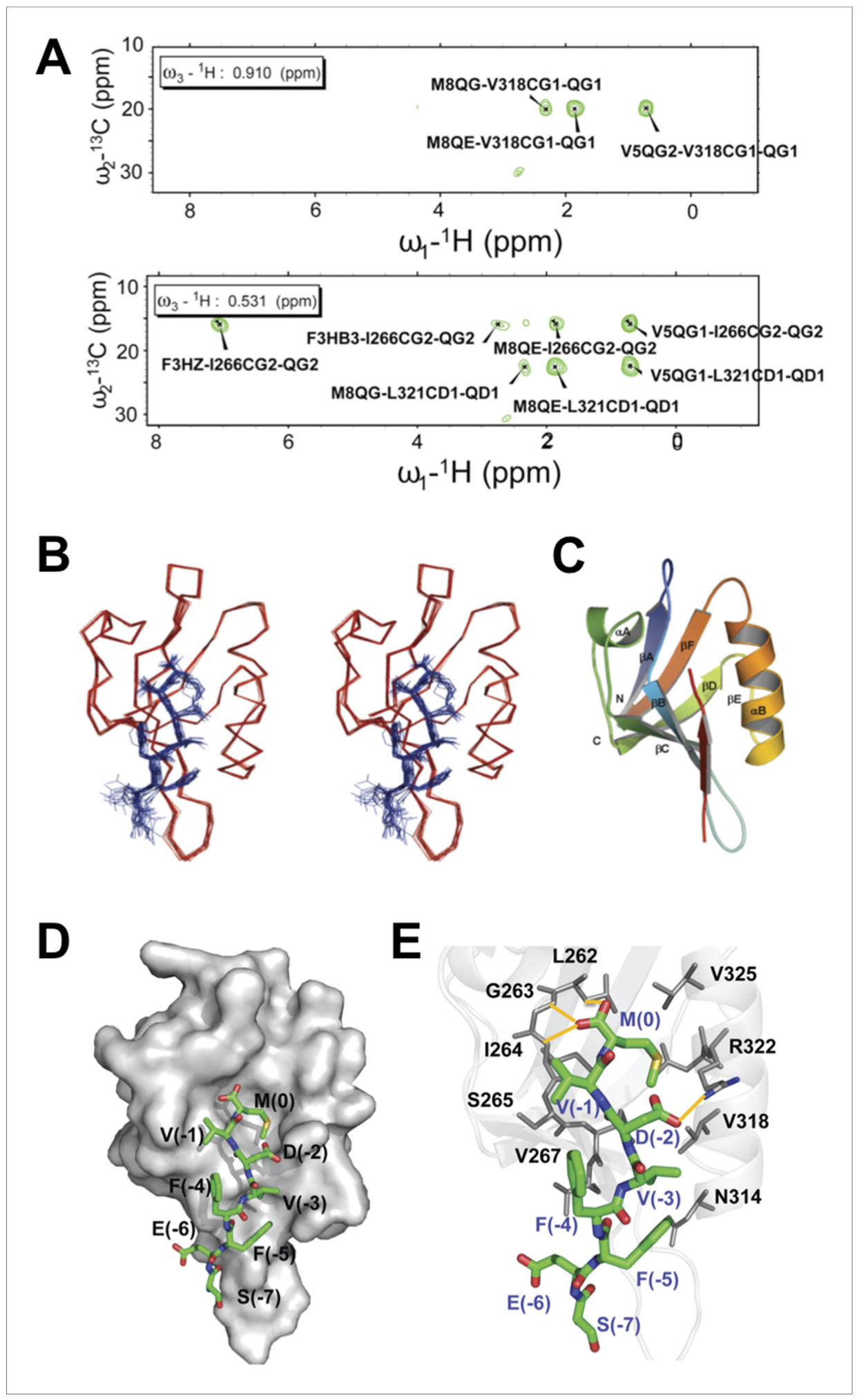

Figure 5. Solution NMR structure of Dvl PDZ domain in complex with Dvl-C peptide. (A) 2D plane of 3D ${ }^{13} \mathrm{C}-\mathrm{F} 1$-half-filtered F2-edited NOESY-HSOC spectrum (mixing time, $300 \mathrm{~ms}$ ) at $15^{\circ} \mathrm{C}$. The ratio of peptide: protein was 10:1. $\left[{ }^{13} \mathrm{C},{ }^{15} \mathrm{~N}\right.$-PDZ $]=\sim 1 \mathrm{mM}$. (B) A stereo view of the backbone of 15 superimposed structures of the Dvl PDZ-Dvl-C peptide complex. (C) Ribbon diagram of the lowest-energy structure of the Dvl PDZ/Dvl-C peptide complex. (D) Surface of Dvl-1 PDZ bound to Dvl-C peptide (carbon, green; nitrogen, blue; sulfur, yellow; oxygen, red; hydrogen atoms are omitted for clarity). (E) Structural details of the Dvl-C peptide-PDZ Figure 5. continued on next page 
Figure 5. Continued

domain complex. The side chain of Asp(-2) in the Dvl-C peptide forms a hydrogen bond with the side chain of Arg322 on the $\alpha \mathrm{B}$-structure.

DOI: 10.7554/eLife.08142.007

The following source data and figure supplement are available for figure 5:

Source data 1. Intermolecular NOEs between the Dvl-C peptide and the PDZ domain obtained from ${ }^{13} \mathrm{C}$-halffiltered NOESY-HSQC spectraa.

DOI: 10.7554/eLife.08142.008

Source data 2. Structure statistics for the 15 lowest-energy peptide-PDZ complexes. DOI: 10.7554/eLife.08142.009

Figure supplement 1. The mutant Dvl-1 PDZ (R322A) domain binds more weakly than wild-type Dvl-1 PDZ domain to the Dvl-C peptide.

DOI: 10.7554/eLife.08142.010

Finally, to further confirm that the effect of Dvl's open conformation on the CE phenotype resulted from JNK activation, we coinjected dnJNK with $X D$ sh-C $\Delta 8$ or $X d d 1$, and analyzed the phenotypes in Xenopus whole embryo. Injection of $X D$ sh-C $\Delta 8$ or $X d d 1$ alone resulted in embryos with short and bent axis, reflecting $C E$ defects. However, the abnormal $C E$ phenotype was substantially rescued when the embryos were coinjected with dnJNK (Figure 91), suggesting that JNK activation induced by the Dvl open conformation (i.e., use of XDsh-C $\Delta 8$ or Xdd1) had resulted in the CE phenotype.

\section{Obstruction of the DvI PDZ domain activates JNK}

Many Wnt signaling regulators directly bind to and inhibit the Dvl PDZ domain (Wharton, 2003; Wallingford and Habas, 2005). To block Wnt signaling transduction at the Dvl level, we also developed a series of small-molecule inhibitors that disrupt Fz-Dvl interaction (Shan et al., 2005, 2012; Grandy et al., 2009; Shan and Zheng, 2009; Lee et al., 2009b). Because all of the Wnt-regulating proteins and small molecule inhibitors target the site on the surface of the DvI PDZ domain that binds to the molecule's own C-terminus, these agents should release the Dvl C-terminus from its intramolecular binding and open the closed conformation of Dvl. These molecules can be used to probe the effect of the conformational change of Dvl. For this study we chose a small molecule inhibitor of Fz-Dvl interaction, compound 3289-8625 (Grandy et al., 2009) and a protein inhibitor of Wnt signaling, TMEM88 (Lee et al., 2010).

We previously showed that the small molecule 3289-8625 penetrates the Xenopus embryo and binds to the PDZ domain of Dvl (Grandy et al., 2009). Microinjection of embryos with XDsh mRNA and incubation in medium containing compound 3289-8625 increased the prevalence of the non-canonical Wnt signaling-associated CE phenotype (Figure 10A). We also previously reported the protein TMEM88 to be a novel Wnt signaling inhibitor whose C-terminal region binds to the DVI PDZ domain (Lee et alo, 2010). When we coinjected embryos with mRNAs encoding the C-terminal half of TMEM88 (TMEM88-C) and wild-type XDsh, abnormal CE phenotypes were again more prevalent than in embryos injected only with XDsh mRNA (Figure 10A); this result is consistent with the fact that gain-of-function of PCP signaling induced by activated Dvl affects gastrulation movements and disrupts axis elongation (Djiane et alo, 2000). CE defects were much less prevalent in control embryos incubated in 3289-8625 or injected with TMEM88-C mRNA alone (Figure 10A).

To further dissect how inhibition of the Dvl PDZ domain affects Dvl's role in the Wnt/ $\beta$-catenin and Wnt/JNK signaling pathways, we used the TOPFLASH and AP1-luciferase reporter assays. To target the Dvl PDZ domain with TMEM88-C, we again coinjected the embryos with mRNAs encoding TMEM88-C and wild-type XDsh. As we reported previously (Lee et al., 2010), binding of the PDZ domain by TMEM88-C antagonized Wnt/ $\beta$-catenin activity induced by Dvl overexpression (Figure 10B). Further, this opening of the Dvl conformation potentiated Wnt/JNK signaling induced by Dvl overexpression (Figure 10C).

\section{Discussion}

Here we showed that a C-terminal motif of Dvl can bind intrinsically to the Dvl PDZ domain, forming a 'closed' conformation. Although the binding affinity of this reaction is not notably 


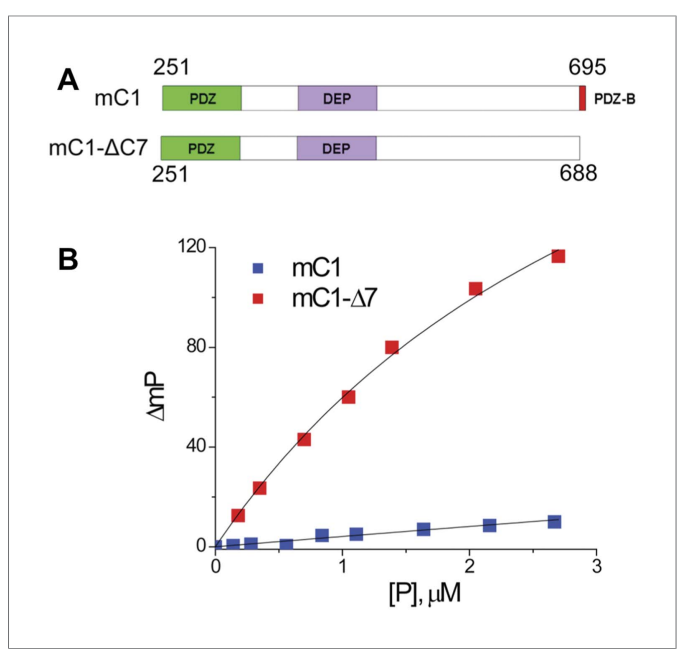

Figure 6. The binding pocket of the Dvl PDZ domain can be occupied by its intrinsic $\mathrm{C}$-terminus. (A) Schematic representation of protein constructs $\mathrm{mC} 1$ (residues 251-695) and $\mathrm{mC1}-\mathrm{C} \Delta 7$ (residues 251-688) sequence. (B) Polarization change of the fluorescencelabeled peptide Rox-DprC (Rox-SGSLKLMTTV, derived from the C-terminus of Dpr) after addition of $\mathrm{mC} 1-\mathrm{C} \Delta 7$ and $\mathrm{mC} 1$ proteins in $50 \mathrm{mM}$ phosphate with $0.3 \mathrm{M} \mathrm{NaCl}$ and $6 \mathrm{mM} \beta$-mercaptoethanol. For the binding of Rox-DprC to $\mathrm{mC1}, \mathrm{KD}$ is $3.8 \pm 0.5 \mu \mathrm{M}$ the value was obtained by fitting the titration data with the equation: $\Delta \mathrm{mP}=\Delta \mathrm{mP}_{\max } \times[\mathrm{P}] /\left([\mathrm{P}]+\mathrm{K}_{\mathrm{D}}\right)$, where $\Delta \mathrm{mP}$ is the polarization change of Rox-DprC, [P] is the concentration of protein, and both $\mathrm{K}_{\mathrm{D}}$ and $\Delta \mathrm{mP}_{\max }$ are the fitting variables. For the binding of Rox-DprC to $\mathrm{mC} 1-\mathrm{C} \Delta 7$, $K_{D}$ was estimated as $68 \pm 5 \mu \mathrm{M}$. Because of the limitation in the titration study, to estimate the $K_{D}$ value, although we used the same equation to fit the titration data, in the fitting, $\mathrm{Kd}$ was the only variable and the maximum polarization change, $\Delta \mathrm{mP}_{\max }$, was fixed to the value that was obtained in the titration study of Rox-DprC binds to $\mathrm{mC} 1-\mathrm{C} \Delta 7$.

DOI: 10.7554/eLife.08142.011 numbered according to the mouse Dvl-1 protein

high, the closed conformation is stable and may predominate among intracellular Dvl proteins (Zhou et al., 2006). To compare the effects of the two Dvl conformations, we examined a C-terminal-truncated Dvl mutant, the established Xdd1 mutant (neither of these forms the 'closed' conformation in solution), and wild-type Dvl in different Xenopus assays and found that both of the 'open' Dvl constructs significantly enhanced the CE phenotype mediated by Wnt-JNK signaling. To further support this observation we observed the competitive binding to the PDZ domain of the Dvl C-terminus and two agents known to bind the Dvl PDZ domain-the peptide TMEM88-C and the small-molecule inhibitor 3289-8625 (Grandy et al., 2009); we reasoned that by competing with the intrinsic binding of the $\mathrm{C}$-terminus, these two agents should induce an open Dvl conformation. Indeed, the two molecules enhanced JNK activation by wild-type Dvl. Interestingly, consistent with these findings, several groups have reported that JNK is activated by sulindac, a nonsteroidal antiinflammatory drug we previously demonstrated to bind to the Dvl PDZ domain (Czibere et al., 2005; Rice et al., 2006; Lee et al., 2009b; Singh et al., 2011). Therefore, we conclude that the open conformation of Dvl is likely to initiate JNK activation.

Dvl has been suggested to exist in activated and inactivated states within the cell and to be activated by Wnt signals (Lee et al., 2003; Wharton, 2003; Wallingford and Habas, 2005; Gao and Chen, 2009); however, the form of the 'active state' has not been determined. Our findings suggest that the activation state of Dvl is determined by its conformation, such that in the absence of Wnt ligand, Dvl adopts a closed conformation that represents its inactive state.

Wnt signaling opens the closed conformation of Dvl and thereby activates Dvl. For example, in a working model of the canonical Wnt signaling pathway, the simultaneous binding of Wnt ligand to both of its membrane-bound receptors, Fz and LRP5/6, initiates canonical Wnt signaling by causing dimerization of the two receptors. Within the cell, the close proximity of the two receptors' cytoplasmic tails triggers the formation of signalosomes (Bilic et al., 2007) containing Dvl and Axin; Dvl binds to Fz through its PDZ domain (Wong et al., 2003), thus acquiring the open conformation. This open conformation also allows the Dvl DEP domain to interact with the membrane through nonspecific charge-charge interactions (Noordermeer et al., 1994; Theisen et al., 1994; Axelrod et al., 1998; Wong et al., 2003; Park et al., 2005; Wang et al., 2006; Schwarz-Romond et al., 2007; Simons et al., 2009) that in turn promote the Fz-Dvl interaction. Axin binds LRP5/6 (Mao et al., 2001; Tamai et al., 2004), and the DIX domains of Dvl and Axin interact to further stabilize the complex (Schwarz-Romond et al., 2007; Fiedler et al., 2011). The network of interactions in the supercomplexes stabilizes the signalosomes remarkably, although the individual interactions are relatively weak. Energetically, the super-complex is more stable than the closed conformation of Dvl and therefore can capture the PDZ domain of Dvl. By ousting the Dvl C-terminus from its bond with the Dvl PDZ domain, the Fz binding motif also opens the conformation of Dvl as it is captured in the signalosome. 


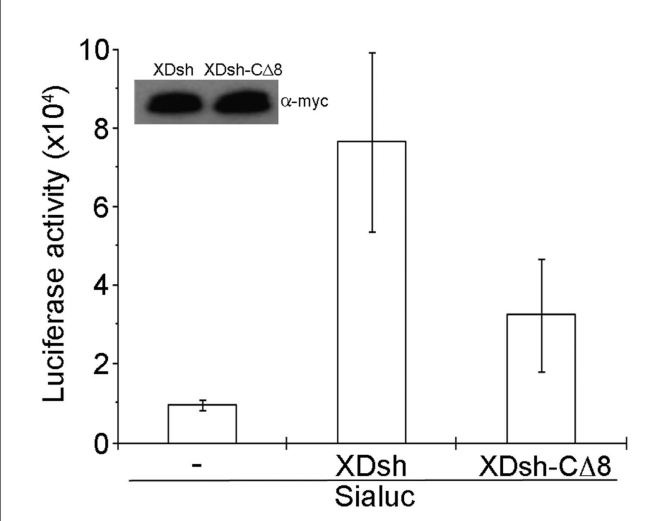

Figure 7. Effect of wild-type XDsh and XDsh-C $\Delta 8$ activity on canonical Wnt signaling. Luciferase assay using a Siamois promoter reporter (Sialuc). Sialuc DNA (200 pg) was injected alone or with myc-tagged Xdsh or $X d s h-C \Delta 8$ mRNA (500 pg) into the animal pole region of 2-cell Xenopus embryos. Ectodermal explants were dissected at the early gastrula stage for luciferase assay. Values are the means $\pm S D$ from four independent experiments $(p<0.05)$. Inset shows a representative western blot using anti-myc antibody (9E10) to control for XDsh and XDsh-C $\Delta 8$ protein expression in the four experiments.

DOI: 10.7554/eLife.08142.012
Although other Wnt signaling pathways are less well defined, it is clear that most, if not all, noncanonical Wnt pathways are triggered by the interaction between $\mathrm{Fz}$ and $\mathrm{Dvl}$, which is likely to open the conformation of Dvl as well (Habas and Dawid, 2005; Gao and Chen, 2009). Therefore, we propose that the active form of Dvl is its open conformation and that this active form initiates JNK-related Wnt signaling pathways.

The DVl DEP domain is essential to activate JNK cascades (Boutros et al., 1998). The hypothesis that 'opened' DVl stimulates JNK activity is consistent with a report that Daam1, a key player that connects Dvl to JNK, exists in an autoinhibited state and is activated by binding to Dvl (Liu et al., 2008). Daam1 binds to the Dvl DEP domain (Habas et al., 2001), which is likely to be obstructed in the closed conformation. Therefore, opening of Dvl's conformation is a key step in the Wnt-stimulated cascade that activates JNK.

\section{Materials and methods}

\section{Protein expression and purification}

The cDNAs encoding the PDZ (residues 251-340), DEP (residues 377-503), mC1 (residues 251-695), and $\mathrm{mD1}-\mathrm{C} \Delta 7$ (residues 251-688) domains of mouse Dvl-1 were sub-cloned into the pET28a vector. The N-terminally 6xHis-tagged proteins were expressed in BL21(DE3) Escherichia coli and purified by Ni-affinity chromatography followed by gel filtration chromatography as we described previously (Wong et al., 2003) and describe in the supplementary information.

\section{Peptide synthesis and purification}

Peptides were synthesized by the Hartwell Center for Bioinformatics \& Biotechnology at St. Jude Children's Research Hospital; they were purified by reverse-phase high-performance liquid chromatography and confirmed by MSI-MS as described in the supplementary information.

\section{Binding studies}

For the fluorescence spectroscopy studies, a Fluorolog-3 spectrofluorometer (HORUBA Instruments Inc, Edison, NJ) with a $10 \times 4 \mathrm{~mm}$ quartz cell (Hellma Inc.) with magnetic stirring was used. To confirm that the binding site of the Dvl-1 PDZ domain was occupied by intrinsic C-terminus, we generated two proteins, $\mathrm{mC} 1$ and $\mathrm{mC} 1-\mathrm{C} \Delta 7$, which were separately titrated into the fluorescence-labeled peptide RoxDprC. The $K_{1}$ of both peptides was determined in two independent experiments by using the equation $K_{D}^{\text {app }}=K_{D}\left(1+[I] / K_{I}\right)$, where $K_{D}^{\text {app }}$ is the apparent $K_{D}$ of Rox-Dpr-C with the Dvl-C or Dsh-C peptide and [I] is the concentration of both peptides (Figure 2). For the ITC studies, Auto-iTC-200 (MicroCal) was used to obtain the binding affinity of Dvl-C peptide and Dvl PDZ protein in $50 \mathrm{mM}$ phosphate buffer. The concentration of Dvl-C peptide in the syringe was $1.05 \mathrm{mM}$ and the concentration of Dvl PDZ domain in the cell was $0.114 \mathrm{mM}$ (Figure 3). The $\mathrm{K}_{\mathrm{D}}$ value was averaged from two independent experiments at $25^{\circ} \mathrm{C}$.

\section{NMR spectroscopy}

All NMR experiments were performed at $15^{\circ} \mathrm{C}$ using Bruker Avance $800-\mathrm{MHz}$ spectrometers equipped with triple-resonance, 5-mm triple axis-shielded gradient probes. For titration experiments we used the Varian Unity INOVA $600 \mathrm{MHz}$ spectrometer equipped with a triple-resonance, 5-mm triple-axis shielded gradient probe at $25^{\circ} \mathrm{C}$. 


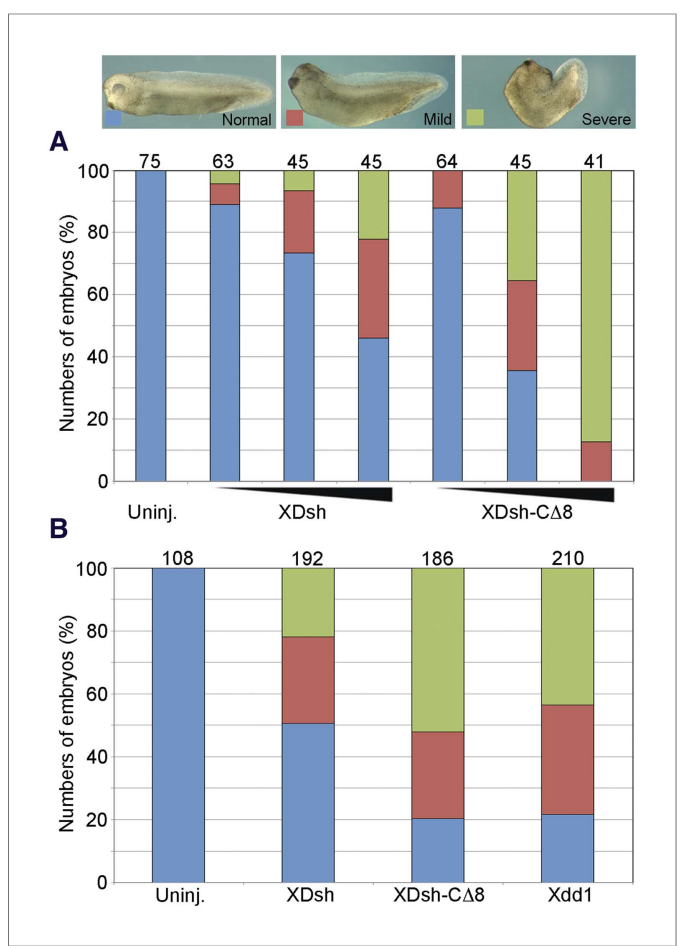

Figure 8. The open conformation of Dvl significantly enhances gain-of-function planar cell polarity (PCP) signaling. (A) Xenopus embryonic abnormal convergent extension (CE) phenotypes induced by injection of wildtype XDsh and XDsh-C $\Delta 8$ mRNA at three increasing concentrations (arrows at bottom represent 80 pg, 200 pg and $500 \mathrm{pg}$ of injected mRNA; above are numbers of embryos injected from two independent experiments). Phenotypes are severe (green), mild (red), and normal (blue). (B) Comparison of phenotypes induced by doseequivalent injections (500 pg mRNA) of XDsh, XDsh-C 48 , and Xdd1 (a well-established dominant-negative XDsh mutant). XDsh-C $\Delta 8$ and $X d d 11$ induced similar phenotypes. The numbers of embryos injected from three independent experiments are listed on the top of each column.

DOI: 10.7554/eLife.08142.013

\section{Structure determination of the Dvl-1 PDZ/Dvl-C peptide complex}

We used NMR-derived data and a simulated annealing protocol using the program CNS within the HADDOCK software (ver. 1.2) (Dominguez et al., 2003). Coordinates of mouse Dvl PDZ were taken from the X-ray structure of the Xenopus PDZ domain (1L6O:A), whose amino acid residues were modified to fit the mouse Dvl PDZ domain (Wong et al., 2003). Two different types of restraints were used to determine the complex structures: (1) Ambiguous interaction restraints were chosen on the basis of the chemical shift perturbation, intermolecular NOEs between the Dvl-C peptide/PDZ complex, and solvent accessibility (calculated by using the program NACCESS [Hubbard and Thornton, 1993]); (2) Unambiguous distant restraints were obtained from several different types of NOESY experiments, including 2D [F1,F2]-double filtered NOESY experiments and 3D F1-half-filtered and F2-edited ${ }^{13} \mathrm{C}-\mathrm{NOESY}-\mathrm{HSOC}$ experiments using the ${ }^{13} \mathrm{C} /{ }^{15} \mathrm{~N}$ PDZ domain of $\mathrm{Dvl}$ with unlabeled Dvl-C peptide. NOE restraints were grouped into distance ranges according to their relative intensity: strong (1.8-2.5 and 1.8-3.0 $\AA$ ), medium (1.8-4.0 ̊), and weak (1.8-5.0 $⿱$ A). A total of 45 unambiguous restraints (23 sequential intramolecular NOEs from the Dvl-C peptide bound to the PDZ domain and 22 intermolecular NOEs between the Dvl-C peptide and the Dvl-1 PDZ domain) were used. Two types of restraints were combined to generate 2000 initial structures of the Dvl PDZ/Dvl-C peptide complex; 200 of these structures were selected by using NOE-derived restraints, and 100 structures were then obtained for final refinement. We ultimately selected the 15 lowest-energy conformers from the final 100 complex structures for further structural analysis.

\section{Xenopus embryos and microinjection of mRNA}

Xenopus eggs were obtained from females previously injected with 500 IU of human chorionic gonadotropin (Sigma) and artificially fertilized. Synthesis, microinjection of capped mRNAs, and treatment of ectodermal explants with activin were previously described (Carron et al., 2005). After microinjection, some embryos were incubated in medium containing $2 \mu \mathrm{g} / \mathrm{ml}$ of the smallmolecule compound 3289-8625 until the desired stage (Grandy et al., 2009).

\section{Luciferase-based assays}

To examine canonical Wnt signaling, both the siamois promoter-driven luciferase reporter (Brannon et al., 1997) and the TOPFLASH luciferase reporter were used. The siamois promoter reporter DNA construct (Sialuc, $200 \mathrm{pg}$ ) or the TOPFLASH reporter DNA construct (200 pg) was injected, alone or with mRNA (500 pg) encoding wild-type XDsh or a mutant XDsh-C $\Delta 8$ lacking the PDZ-binding motif, into the animal pole region of 2-cell Xenopus embryos. Ectodermal explants were dissected from 

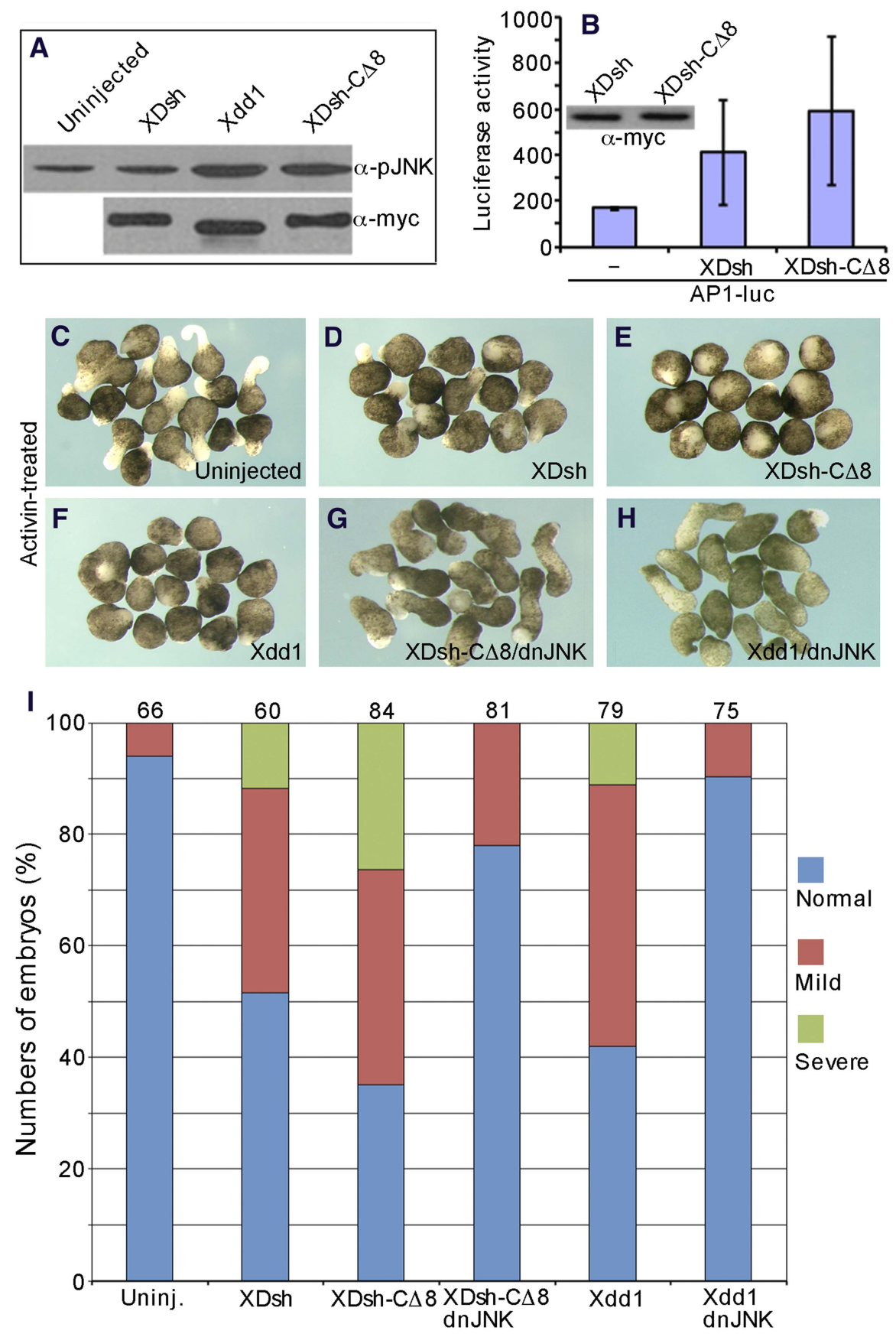

Figure 9. The open conformation of Dvl disrupts CE by activating Jun N-terminal kinase (JNK). (A) Western blot of phosphorylated JNK in ventral mesoderm cells overexpressing wild-type XDsh or its mutants. At equivalent protein level, Xdd1 and XDsh-C $\Delta 8$ more potently induce JNK phosphorylation than wild-type XDsh. (B) Xenopus 4-cell stage embryos were dorsally coinjected with equal quantities of wild-type XDsh mRNA or XDsh-C 48 mRNA (500 pg) and the AP1-luciferase reporter DNA (200 pg); luciferase activity was assayed at the late gastrula stage. Inset shows a representative Western blot using anti-myc antibody to control XDsh and XDsh-C $\Delta 8$ protein levels. Values are the mean and SD from three independent experiments (XDsh vs XDsh-C $\Delta 8, \mathrm{p}<0.05$ ). (C-H) The dominant negative JNK mutant (dnJNK) rescues activin-induced explant elongation blocked by overexpression of XDsh-C $\Delta 8$ or Xdd1. (C) Uninjected explants treated with activin show extensive elongation. (D) XDsh-injected explants treated with activin show moderate inhibition of explant elongation. (E) Injection of XDsh-C $\Delta 8$ strongly inhibits explant elongation. (F) Injection of $X d d 1$ similarly inhibits explant elongation as injection of $X D$ sh-C $\Delta 8$. $(\mathbf{G}, \mathbf{H})$ dnJNK rescues Figure 9. continued on next page 
Figure 9. Continued

explant elongation inhibited by XDsh-C $\Delta 8$ or Xdd1. (I) dnJNK also recues CE defects produced by overexpression of XDsh-C $\Delta 8$ or Xdd1 in whole embryos. Phenotypes are severe (green), mild (red), and normal (blue). Numbers on the top indicate total embryos scored from three independent experiments.

DOI: 10.7554/eLife.08142.014

injected embryos at the late blastula stage. To assess non-canonical Wnt signaling, we used the AP1-luciferase reporter (Rui et al., 2007) to monitor activation of JNK in Xenopus whole embryos. The reporter DNA (200 pg) was injected alone or coinjected with equal quantities (500 pg) of $X D$ sh-C $\Delta 8$ or wild-type XDsh mRNA into the dorsal region of 4-cell Xenopus embryos, which were allowed to develop to late gastrula stage. A Lumat LB9507 luminometer (Berthold Technologies $\mathrm{GmbH} \& \mathrm{Co}$ ) was used to perform the luciferase assays (Promega). We used cell lysates from 10 explants or five whole embryos to measure luciferase activity. All experiments were performed at least in triplicate using different batches of embryos and the mean value was calculated
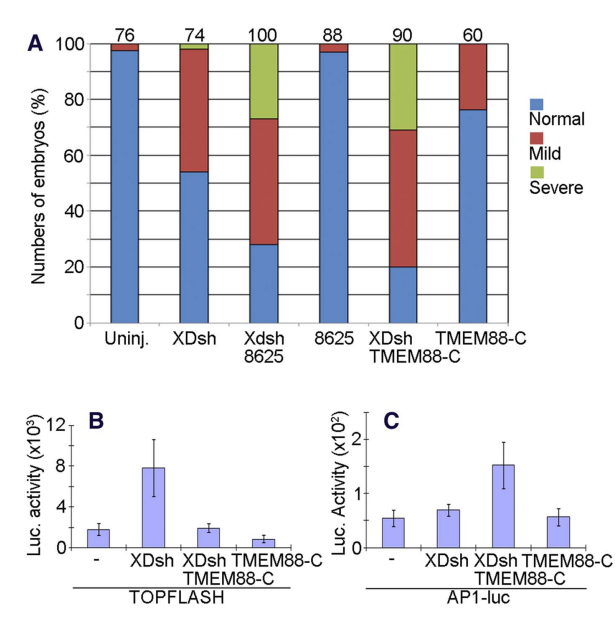

Figure 10. The open conformation of Dvl induced by targeting the Dvl PDZ domain potentiates Wnt/JNK signaling. (A) Regulation of XDsh-mediated PCP signaling by a PDZ-binding small molecule or peptide is shown by the gain-of-function CE phenotypes of whole embryos that were uninjected (controls) or injected with XDsh mRNA with or without treatment with the Dvl inhibitors 3209-8625 or coinjected with XDsh and TMEM88-C mRNAs. (B) Inhibiting the Dvl PDZ domain blocks canonical Wnt signalling induced by Dvl overexpression. Wild-type XDsh mRNA was injected alone or coinjected with an equal quantity of TMEM88-C mRNA in the animal pole region of two-cell stage Xenopus embryos, and ectodermal explants were dissected at the late blastula stage. TOPFLASH luciferase activity values are the mean and SD from three independent experiments $(p<0.05)$. (C) Inhibition of the DVI PDZ domain by TMEM88 opens the conformation of Dvl and potentiates Wnt/JNK signaling induced by Dvl overexpression. Xenopus 4-cell stage embryos were injected dorsally with wild-type XDsh mRNA or coinjected with equal quantities of wild-type XDsh mRNA and TMEM88-C mRNA. AP1 luciferase activity was assayed at the late gastrula stage. Values are the mean and SD from three independent experiments $(p<0.05)$. DOI: 10.7554/eLife.08142.015 using Student's t-test.

\section{Western blot assays}

Synthetic mRNAs (500 pg) corresponding to myc-tagged wild-type XDsh and different mutants were injected into the ventral blastomeres of Xenopus embryos at the 4-cell stage. At the early gastrula stage, 10 ventral mesoderm explants were dissected and analyzed by western blot using anti-phospho-JNK (Thr183/Tyr185, Thr221/Tyr223) antibody (Millipore) and anti-myc 9E10 antibody (Santa-Cruz Biotechnology).

\section{Xenopus whole embryo and ectodermal explant studies}

The two dorsal blastomeres of 4-cell Xenopus embryos were injected with mRNA (500 pg) encoding XDsh, $\mathrm{XDsh}-\mathrm{C} \Delta 8$, or $\mathrm{Xdd} 1$, either alone or with mRNA (500 pg) encoding dnJNK. For the dose-depending studies, three different amounts of XDsh and XDsh-C $\Delta 8$ mRNAs (80 pg, 200 pg and $500 \mathrm{pg}$ ) were used. The embryos were cultured to the larval stage, then grouped and counted according to normal, mild, or severe CE abnormal (JNK gain-of-function) phenotype. To investigate the effect of XDsh, XDsh-C $\Delta 8$, and $X d d 1$ on $C E$ in vitro, the same mRNAs were injected, alone or with dnJNK mRNA, into the animal pole region of 2-cell Xenopus embryos. Ectodermal explants were dissected at the early blastula stage, incubated with activin for $1 \mathrm{hr}$, cultured to the early neurula-stage equivalent, and examined for the extent of explant elongation. To investigate how the $\mathrm{C}$-terminal region of TMEM88 affects Dvl function, equal amounts of mRNAs (500 pg) encoding the C-terminal half of TMEM88 (TMEM88-C) and wild-type XDsh were coinjected into the two dorsal blastomeres 
at the 4-cell stage, and the embryos were again grouped and counted as having normal, mild, or severe CE phenotypes. The above experiments were performed at least twice using different batches of embryos.

\section{Acknowledgements}

We thank the St. Jude Hartwell Center for Bioinformatics and Biotechnology for computational time and peptide synthesis (Scott Malone and Mi Zhou for computer-related technical support and Robert Cassell and Dr Patrick Rodrigues for peptide synthesis). We thank Drs Weixing Zhang and Royappa Grace for assistance with NMR experiments; Youming Shao, Cristina Guibao, S Sokol, SC Lin and D Kimelman for plasmids; and Sharon Naron for editing the manuscript. This work was supported by NIH grants CA21765 (Cancer Center Support Grant) and GM081492, the American Lebanese Syrian Associated Charities (ALSAC) and an unrestricted grant from Research to Prevent Blindness (JJZ), and by grants from the Association Française contre les Myopathies, Ligue Nationale Contre le Cancer, Association pour la Recherche sur le Cancer, Agence Nationale de la Recherche (ANR-09-BLAN-0262-03), and the National Natural Science Foundation of China (31271556, 31471360) (DLS).

\section{Additional information}

Funding

\begin{tabular}{|c|c|c|}
\hline Funder & Grant reference & Author \\
\hline $\begin{array}{l}\text { National Institute of General } \\
\text { Medical Sciences (NIGMS) }\end{array}$ & GM081492 & Jie J Zheng \\
\hline National Cancer Institute (NCl) & CA21765 & Jie J Zheng \\
\hline $\begin{array}{l}\text { Agence Nationale de la } \\
\text { Recherche (L' Agence Nationale } \\
\text { de la Recherche) }\end{array}$ & ANR-09-BLAN-0262-03 & De-Li Shi \\
\hline $\begin{array}{l}\text { Research to Prevent } \\
\text { Blindness (RPB) }\end{array}$ & JSEI & Jie J Zheng \\
\hline $\begin{array}{l}\text { National Natural Science } \\
\text { Foundation of China }\end{array}$ & 31271556 & De-Li Shi \\
\hline $\begin{array}{l}\text { National Natural Science } \\
\text { Foundation of China }\end{array}$ & 31471360 & De-Li Shi \\
\hline
\end{tabular}

The funders had no role in study design, data collection and interpretation, or the decision to submit the work for publication.

Author contributions

H-JL, D-LS, Acquisition of data, Analysis and interpretation of data; JJZ, Conception and design, Analysis and interpretation of data, Drafting or revising the article

Author ORCIDs

Jie J Zheng, (iD http://orcid.org/0000-0001-6524-6800

\section{References}

Angers S, Moon RT. 2009. Proximal events in Wnt signal transduction. Nature Reviews Molecular Cell Biology 10: 468-477. doi: 10.1038/nrm2717.

Axelrod JD, Miller JR, Shulman JM, Moon RT, Perrimon N. 1998. Differential recruitment of Dishevelled provides signaling specificity in the planar cell polarity and Wingless signaling pathways. Genes \& Development 12 : 2610-2622. doi: 10.1101/gad.12.16.2610.

Bilic J, Huang YL, Davidson G, Zimmermann T, Cruciat CM, Bienz M, Niehrs C. 2007. Wnt induces LRP6 signalosomes and promotes Dishevelled-dependent LRP6 phosphorylation. Science 316:1619-1622. doi: 10. 1126/science.1137065.

Boutros M, Mlodzik M. 1999. Dishevelled: at the crossroads of divergent intracellular signaling pathways. Mechanisms of Development 83:27-37. doi: 10.1016/S0925-4773(99)00046-5.

Boutros M, Paricio N, Strutt DI, Mlodzik M. 1998. Dishevelled activates JNK and discriminates between JNK pathways in planar polarity and wingless signaling. Cell 94:109-118. doi: 10.1016/S0092-8674(00)81226-X. 
Brannon M, Gomperts M, Sumoy L, Moon RT, Kimelman D. 1997. A beta-catenin/XTcf-3 complex binds to the siamois promoter to regulate dorsal axis specification in Xenopus. Genes \& Development 11:2359-2370. doi: 10. 1101/gad.11.18.2359.

Carron C, Bourdelas A, Li HY, Boucaut JC, Shi DL. 2005. Antagonistic interaction between IGF and Wnt/JNK signaling in convergent extension in Xenopus embryo. Mechanisms of Development 122:1234-1247. doi: 10. 1016/j.mod.2005.06.007.

Cheyette BN, Waxman JS, Miller JR, Takemaru K, Sheldahl LC, Khlebtsova N, Fox EP, Earnest T, Moon RT. 2002. Dapper, a Dishevelled-associated antagonist of beta-catenin and JNK signaling, is required for notochord formation. Developmental Cell 2:449-461. doi: 10.1016/S1534-5807(02)00140-5.

Czibere A, Prall WC, Zerbini LF, Grall F, Craigie EC, Ulrich SD, Giagounidis AA, Haas R, Libermann TA, Aivado M. 2005. The nonsteroidal anti-inflammatory drug Exisulind selectively induces apoptosis via JNK in secondary acute myeloid leukemia after myelodysplastic syndrome. Cell Cycle 4:812-817. doi: 10.4161/cc.4.6.1722.

Djiane A, Riou J, Umbhauer M, Boucaut J, Shi D. 2000. Role of frizzled 7 in the regulation of convergent extension movements during gastrulation in Xenopus laevis. Development 127:3091-3100.

Dominguez C, Boelens R, Bonvin AM. 2003. HADDOCK: a protein-protein docking approach based on biochemical or biophysical information. Journal of the American Chemical Society 125:1731-1737. doi: 10.1021/ja026939x.

Fiedler M, Mendoza-Topaz C, Rutherford TJ, Mieszczanek J, Bienz M. 2011. Dishevelled interacts with the DIX domain polymerization interface of Axin to interfere with its function in down-regulating beta-catenin. Proceedings of the National Academy of Sciences of USA 108:1937-1942. doi: 10.1073/pnas.1017063108.

Gao C, Cao W, Bao L, Zuo W, Xie G, Cai T, Fu W, Zhang J, Wu W, Zhang X, Chen YG. 2010. Autophagy negatively regulates Wnt signalling by promoting Dishevelled degradation. Nature Cell Biology 12:781-790. doi: 10.1038/ncb2082.

Gao C, Chen YG. 2009. Dishevelled: the hub of Wnt signaling. Cellular Signalling 22:717-727. doi: 10.1016/j. cellsig.2009.11.021.

Grandy D, Shan J, Zhang X, Rao S, Akunuru S, Li H, Zhang Y, Alpatov I, Zhang XA, Lang RA, Shi DL, Zheng JJ. 2009. Discovery and characterization of a small molecule inhibitor of the PDZ domain of dishevelled. The Journal of Biological Chemistry 284:16256-16263. doi: 10.1074/jbc.M109.009647.

Habas R, Dawid IB. 2005. Dishevelled and Wnt signaling: is the nucleus the final frontier? Journal of Biology 4:2. doi: 10.1186/jbiol22.

Habas R, Kato Y, He X. 2001. Wnt/Frizzled activation of Rho regulates vertebrate gastrulation and requires a novel Formin homology protein Daam1. Cell 107:843-854. doi: 10.1016/S0092-8674(01)00614-6.

Hubbard SJ, Thornton JM. 1993. NACCESS. Department of Biochemistry and Molecular Biology, University College London.

Jones C, Chen P. 2007. Planar cell polarity signaling in vertebrates. BioEssays 29:120-132. doi: 10.1002/bies.20526.

Lee E, Salic A, Kruger R, Heinrich R, Kirschner MW. 2003. The roles of APC and Axin derived from experimental and theoretical analysis of the Wnt pathway. PLOS Biology 1:E10. doi: 10.1371/journal.pbio.0000010.

Lee HJ, Finkelstein D, Li X, Wu D, Shi DL, Zheng JJ. 2010. Identification of transmembrane protein 88 (TMEM88) as a Dishevelled-binding protein. The Journal of Biological Chemistry 285:41549-41556. doi: 10.1074/jbc.M110.193383.

Lee HJ, Wang NX, Shao Y, Zheng JJ. 2009a. Identification of tripeptides recognized by the PDZ domain of Dishevelled. Bioorganic \& Medicinal Chemistry 17:1701-1708. doi: 10.1016/j.bmc.2008.12.060.

Lee HJ, Wang NX, Shi DL, Zheng JJ. 2009b. Sulindac inhibits canonical Wnt signaling by blocking the PDZ domain of the protein Dishevelled. Angewandte Chemie 48:6448-6452. doi: 10.1002/anie.200902981.

Lee HJ, Zheng JJ. 2010. PDZ domains and their binding partners: structure, specificity, and modification. Cell Communication and Signaling 8:8. doi: 10.1186/1478-811X-8-8.

Li L, Yuan H, Xie W, Mao J, Caruso AM, McMahon A, Sussman DJ, Wu D. 1999. Dishevelled proteins lead to two signaling pathways. Regulation of LEF-1 and c-Jun N-terminal kinase in mammalian cells. The Journal of Biological Chemistry 274:129-134. doi: 10.1074/jbc.274.1.129.

Liu W, Sato A, Khadka D, Bharti R, Diaz H, Runnels LW, Habas R. 2008. Mechanism of activation of the Formin protein Daam1. Proceedings of the National Academy of Sciences of USA 105:210-215. doi: 10.1073/pnas.0707277105.

Logan CY, Nusse R. 2004. The wnt signaling pathway in development and disease. Annual Review of Cell and Developmental Biology 20:781-810. doi: 10.1146/annurev.cellbio.20.010403.113126.

Mao J, Wang J, Liu B, Pan W, Farr GH III, Flynn C, Yuan H, Takada S, Kimelman D, Li L, Wu D. 2001. Low-density lipoprotein receptor-related protein-5 binds to Axin and regulates the canonical Wnt signaling pathway. Molecular Cell 7:801-809. doi: 10.1016/S1097-2765(01)00224-6.

Moriguchi T, Kawachi K, Kamakura S, Masuyama N, Yamanaka H, Matsumoto K, Kikuchi A, Nishida E. 1999. Distinct domains of mouse dishevelled are responsible for the c-Jun N-terminal kinase/stress-activated protein kinase activation and the axis formation in vertebrates. The Journal of Biological Chemistry 274:30957-30962. doi: 10.1074/jbc.274.43.30957.

Noordermeer J, Klingensmith J, Perrimon N, Nusse R. 1994. Dishevelled and armadillo act in the wingless signalling pathway in Drosophila. Nature 367:80-83. doi: 10.1038/367080a0.

Park TJ, Gray RS, Sato A, Habas R, Wallingford JB. 2005. Subcellular localization and signaling properties of Dishevelled in developing vertebrate embryos. Current Biology 15:1039-1044. doi: 10.1016/j.cub.2005.04.062.

Rice PL, Peters SL, Beard KS, Ahnen DJ. 2006. Sulindac independently modulates extracellular signal-regulated kinase 1/2 and cyclic GMP-dependent protein kinase signaling pathways. Molecular Cancer Therapeutics $\mathbf{5}$ : 746-754. doi: 10.1158/1535-7163.MCT-05-0210.

Rui Y, Xu Z, Xiong B, Cao Y, Lin S, Zhang M, Chan SC, Luo W, Han Y, Lu Z, Ye Z, Zhou HM, Han J, Meng A, Lin SC. 2007. A beta-catenin-independent dorsalization pathway activated by Axin/JNK signaling and antagonized by aida. Developmental Cell 13:268-282. doi: 10.1016/j.devcel.2007.07.006. 
Schwarz-Romond T, Fiedler M, Shibata N, Butler PJ, Kikuchi A, Higuchi Y, Bienz M. 2007. The DIX domain of Dishevelled confers Wnt signaling by dynamic polymerization. Nature Structural \& Molecular Biology 14:484-492. doi: 10.1038/nsmb1247.

Shan J, Shi DL, Wang J, Zheng J. 2005. Identification of a specific inhibitor of the Dishevelled PDZ domain. Biochemistry 44:15495-15503. doi: 10.1021/bi0512602.

Shan J, Zhang X, Bao J, Cassell R, Zheng JJ. 2012. Synthesis of potent Dishevelled PDZ domain inhibitors guided by virtual screening and NMR studies. Chemical Biology \& Drug Design 79:376-383. doi: 10.1111/j.1747-0285. 2011.01295.x.

Shan J, Zheng JJ. 2009. Optimizing Dvl PDZ domain inhibitor by exploring chemical space. Journal of Computeraided Molecular Design 23:37-47. doi: 10.1007/s10822-008-9236-1.

Simons M, Gault WJ, Gotthardt D, Rohatgi R, Klein TJ, Shao Y, Lee HJ, Wu AL, Fang Y, Satlin LM, Dow JT, Chen J, Zheng J, Boutros M, Mlodzik M. 2009. Electrochemical cues regulate assembly of the Frizzled/Dishevelled complex at the plasma membrane during planar epithelial polarization. Nature Cell Biology 11:286-294. doi: 10. 1038/ncb1836.

Singh R, Cadeddu RP, Frobel J, Wilk CM, Bruns I, Zerbini LF, Prenzel T, Hartwig S, Brunnert D, Schroeder T, Lehr S, Haas R, Czibere A. 2011. The non-steroidal anti-inflammatory drugs Sulindac sulfide and Diclofenac induce apoptosis and differentiation in human acute myeloid leukemia cells through an AP-1 dependent pathway. Apoptosis 16:889-901. doi: 10.1007/s10495-011-0624-y.

Sokol S. 2000. A role for Wnts in morphogenesis and tissue polarity. Nature Cell Biology 2:E124-E126. doi: 10. $1038 / 35017136$.

Sokol SY. 1996. Analysis of Dishevelled signalling pathways during Xenopus development. Current Biology 6: 1456-1467. doi: 10.1016/S0960-9822(96)00750-6.

Sokol SY, Klingensmith J, Perrimon N, Itoh K. 1995. Dorsalizing and neuralizing properties of Xdsh, a maternally expressed Xenopus homolog of dishevelled. Development 121:3487.

Tamai K, Zeng X, Liu C, Zhang X, Harada Y, Chang Z, He X. 2004. A mechanism for Wnt coreceptor activation. Molecular Cell 13:149-156. doi: 10.1016/S1097-2765(03)00484-2.

Tauriello DV, Jordens I, Kirchner K, Slootstra JW, Kruitwagen T, Bouwman BA, Noutsou M, Rudiger SG, Schwamborn K, Schambony A, Maurice MM. 2012. Wnt/beta-catenin signaling requires interaction of the Dishevelled DEP domain and $C$ terminus with a discontinuous motif in Frizzled. Proceedings of the National Academy of Sciences of USA 109:E812-E820. doi: 10.1073/pnas.1114802109.

Theisen H, Purcell J, Bennett M, Kansagara D, Syed A, Marsh JL. 1994. Dishevelled is required during wingless signaling to establish both cell polarity and cell identity. Development 120:347-360.

Tonikian R, Zhang Y, Sazinsky SL, Currell B, Yeh JH, Reva B, Held HA, Appleton BA, Evangelista M, Wu Y, Xin X, Chan AC, Seshagiri S, Lasky LA, Sander C, Boone C, Bader GD, Sidhu SS. 2008. A specificity map for the PDZ domain family. PLOS Biology 6:e239. doi: 10.1371/journal.pbio.0060239.

Umbhauer M, Djiane A, Goisset C, Penzo-Mendez A, Riou JF, Boucaut JC, Shi DL. 2000. The C-terminal cytoplasmic Lys-thr-X-X-X-Trp motif in frizzled receptors mediates Wnt/beta-catenin signalling. The EMBO Journal 19:4944-4954. doi: 10.1093/emboj/19.18.4944.

Wallingford JB, Habas R. 2005. The developmental biology of Dishevelled: an enigmatic protein governing cell fate and cell polarity. Development 132:4421-4436. doi: 10.1242/dev.02068.

Wang J, Hamblet NS, Mark S, Dickinson ME, Brinkman BC, Segil N, Fraser SE, Chen P, Wallingford JB, WynshawBoris A. 2006. Dishevelled genes mediate a conserved mammalian PCP pathway to regulate convergent extension during neurulation. Development 133:1767-1778. doi: 10.1242/dev.02347.

Wharton KA Jr. 2003. Runnin with the Dvl: proteins that associate with Dsh/Dvl and their significance to Wnt signal transduction. Developmental Biology 253:1-17. doi: 10.1006/dbio.2002.0869.

Wong HC, Bourdelas A, Krauss A, Lee HJ, Shao YM, Wu D, Mlodzik M, Shi DL, Zheng J. 2003. Direct binding of the PDZ domain of Dishevelled to a conserved internal sequence in the C-terminal region of Frizzled. Molecular Cell 12:1251-1260. doi: 10.1016/S1097-2765(03)00427-1.

Yamanaka H, Moriguchi T, Masuyama N, Kusakabe M, Hanafusa H, Takada R, Takada S, Nishida E. 2002. JNK functions in the non-canonical Wnt pathway to regulate convergent extension movements in vertebrates. EMBO Reports 3:69-75. doi: 10.1093/embo-reports/kvf008.

Zhou Z, Feng H, Bai Y. 2006. Detection of a hidden folding intermediate in the focal adhesion target domain: implications for its function and folding. Proteins 65:259-265. doi: 10.1002/prot.21107. 